\title{
A combined continuous microflow photochemistry and asymmetric organocatalysis approach for the enantioselective synthesis of tetrahydroquinolines
}

\author{
Erli Sugiono* and Magnus Rueping ${ }^{*}$
}

\section{Full Research Paper}

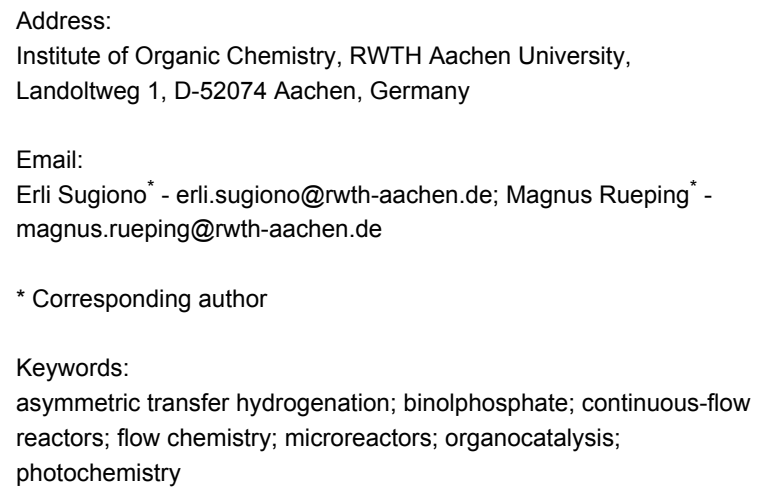

\begin{abstract}
A continuous-flow asymmetric organocatalytic photocyclization-transfer hydrogenation cascade reaction has been developed. The new protocol allows the synthesis of tetrahydroquinolines from readily available 2-aminochalcones using a combination of photochemistry and asymmetric Brønsted acid catalysis. The photocylization and subsequent reduction was performed with catalytic amount of chiral BINOL derived phosphoric acid diester and Hantzsch dihydropyridine as hydrogen source providing the desired products in good yields and with excellent enantioselectivities.
\end{abstract}

\section{Introduction}

Tetrahydroquinolines [1-4] represent a well-known structural motif found in a large number of biologically active natural products. Optically active tetrahydroquinolines are important building blocks for the pharmaceutical and agrochemical industries. Due to their importance, new and efficient procedures for their synthesis have been developed. Among the synthetic protocols developed for the preparation of optically active tetrahydroquinolines, the asymmetric hydrogenation of substi-

tuted quinolines represents the most widely used and efficient method to prepare this class of N-heterocyclic compound [5-17].

In the past years, continuous-flow chemistry has received considerable attention and microstructured continuous-flow devices have emerged as useful devices for different chemical reactions [18-22]. Microreactor technology offers numerous 
practical advantages such as better reaction yield due to enhanced mixing quality, better control of reaction variables, reduced safety hazards, reduced reagent consumption, enhanced heat and mass transfer due to the high surface-to-volume ratio and rapid experimentation and optimization.

Recently, microreactor devices have been adopted for photochemical applications and microflow photochemistry has emerged as efficient synthesis tool [23-31]. The narrow inner dimensions of microfabricated reactors is advantageous for photochemical synthesis since it allows better light penetration and uniform irradiation through the entire reactor and the complete reaction medium, in comparison with reactions performed in conventional batch systems.
Here we report the development of continuous-flow photochemical reaction in combination with asymmetric Brønsted acid catalysis for the synthesis of optically active tetrahydroquinolines. Readily available substituted 2-aminochalcones were envisioned to undergo photocyclization to the corresponding quinolines which in the presence of a chiral BINOLderived phosphoric acid diester and Hantzsch dihydropyridine as hydride donor [32-37] could provide the desired enantioenriched tetrahydroquinolines (Scheme 1) [38].

\section{Results and Discussion}

The continuous-flow microreactor system for the experiment was set up according to Scheme 2. The flow device was set up with multiple commercially available glass reactors connected

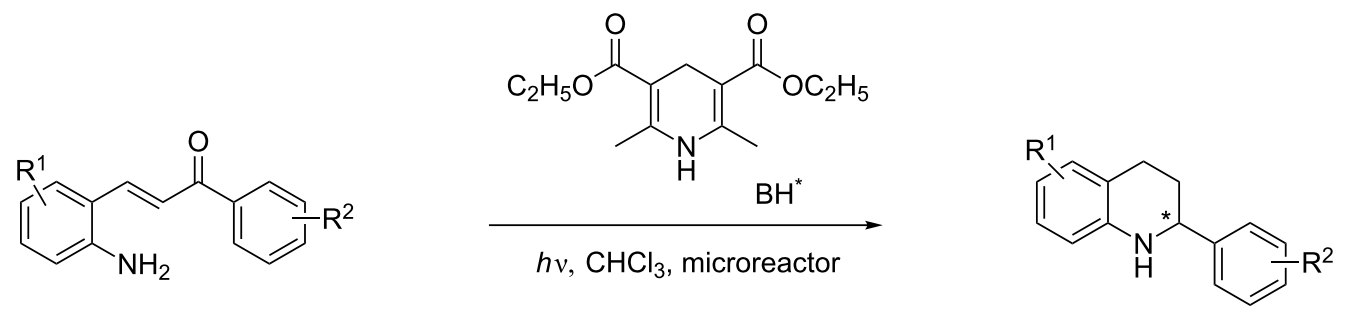

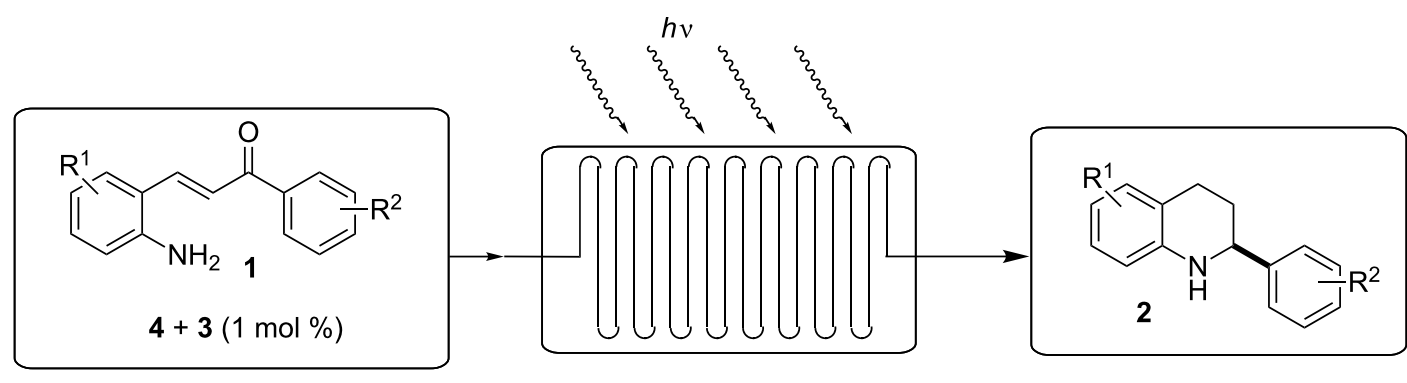

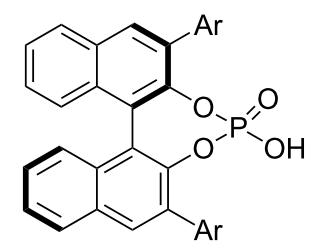

3

Ar: 2,4,6-iPr- $\mathrm{C}_{6} \mathrm{H}_{2}$<smiles>CCOC(=O)C1=C(C)NC(C)=C(C(=O)OC)C1</smiles>

4

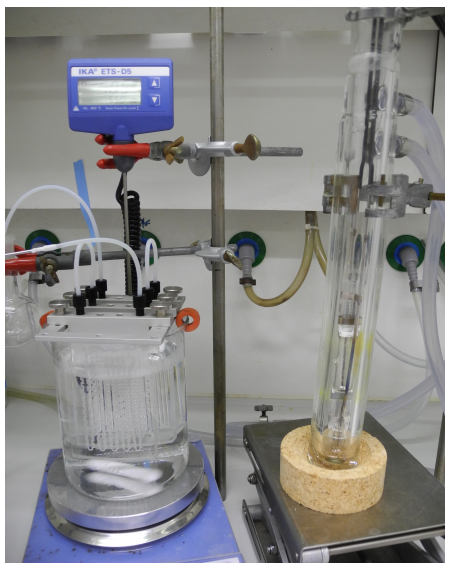


in parallel and placed in a water bath [39]. The light required to perform the reaction is supplied from a high-pressure mercury lamp located outside of the reactor. The lamp consists of a double-jacketed water-cooled pyrex immersion well. The reagents were degassed and introduced into the microreactor using a programmable syringe pump. The product solution was collected in a flask wrapped with aluminium foil to prevent further irradiation.

Our initial investigation of reaction conditions involved the photocyclization-reduction cascade of 2-aminochalcone 1a in the presence of Hantzsch dihydropyridine $\mathbf{4}$ as hydrogen source and catalytic amount of chiral Brønsted acid 3. The effect of temperature, flow rate and concentration on the reaction yield and enantioselectivity are summarized in Table 1. As shown in Table 1, performing the reaction in a pyrex test tube (i.d.: $12 \mathrm{~mm} ; \lambda>300 \mathrm{~nm}$ ) with $1 \mathrm{~mol} \%$ of Brønsted acid 3 at $40{ }^{\circ} \mathrm{C}$ for $60 \mathrm{~min}$ afforded the product in $7 \%$ isolated yield and $95 \%$ enantioselectivity (Table 1 , entry 2 ). Conducting the reaction using the same light source and under the same reaction conditions in a single pass flow reaction showed a noticeable impact on the yield as the product 2 a could be isolated in 59\% yield and $93 \%$ enantiomeric excess (Table 1 , entry 1 vs entry 2 ). Improvement of the reaction yield shows the superior performance of the microflow reactor since the light penetration through the microchannels was significantly increased. A slight improvement of yield was achieved when the reaction was carried out at $55^{\circ} \mathrm{C}$ (Table 1, entry 3 ).
Noticeable improvement on the chemical yield was observed when the reaction was conducted at a lower concentration providing the product in $74 \%$ isolated yield and $94 \%$ enantiomeric excess (Table 1, entry 4 vs entry 3 ). Further decrease of the concentration to $0.03 \mathrm{M}$ gave the best result affording the product in $82 \%$ yield (Table 1 , entry 6 ). It is worth mentioning that decreasing the flow rate had only a minimum effect on the yield but resulted in significant loss of enantioselectivity (Table 1, entry 5 vs 4 ). This result indicates that the residence time plays a crucial role in this photocyclization-reduction cascade. Due to prolonged irradiation of the reaction mixture, an undesired background reaction initiated by photoexcited dihydropyridine occurred leading to the loss of enantioselectivity $[40,41]$.

With the optimized reaction conditions in hand, the substrate scope of this new photocyclization-asymmetric transfer hydrogenation sequence was examined. The results are summarized in Table 2. In general, different 2-aminochalcones bearing substituted aromatic residues on both ketone and enone moieties underwent the desired photocyclization and subsequent asymmetric reduction to afford the corresponding tetrahydroquinolines in good yields and high enantioselectivities.

\section{Conclusion}

In conclusion, we have demonstrated the great potential of a new continuous-flow microreactor system for the photocyclization-reduction cascade of 2-aminochalcones. Under the contin-

Table 1: Optimization of the Brønsted acid catalyzed transfer hydrogenation of quinolines. ${ }^{a}$

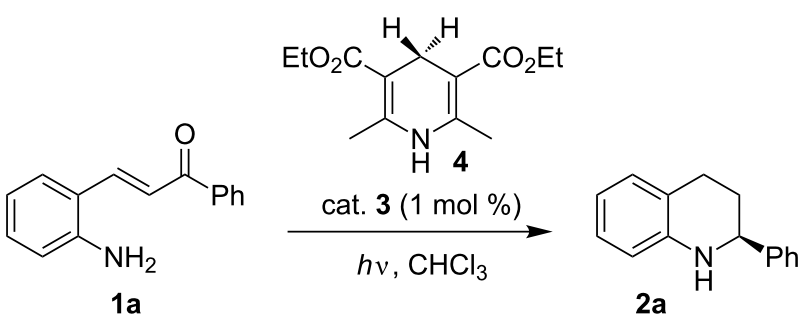

\begin{tabular}{|c|c|c|c|c|c|c|}
\hline Entry & Conc. [mol/L] & Temp. $\left[{ }^{\circ} \mathrm{C}\right]$ & Time [min] & Flow rate $\left[\mathrm{mL} \mathrm{min}^{-1}\right]$ & Yield $[\%]^{b}$ & ee $[\%]^{c}$ \\
\hline 1 & 0.1 & 40 & 60 & 0.1 & 59 & 93 \\
\hline $2^{d}$ & 0.1 & 40 & 60 & batch & 7 & 95 \\
\hline 3 & 0.1 & 55 & 60 & 0.1 & 64 & 96 \\
\hline 4 & 0.05 & 55 & 60 & 0.1 & 74 & 94 \\
\hline 5 & 0.05 & 55 & 120 & 0.05 & 79 & 88 \\
\hline 6 & 0.03 & 55 & 60 & 0.1 & 82 & 94 \\
\hline $7^{d}$ & 0.03 & 55 & 60 & batch & 29 & 96 \\
\hline 8 & 0.03 & 55 & 120 & 0.05 & 88 & 83 \\
\hline
\end{tabular}

aReaction conditions: 1a, 4 (2.4 equiv), 3 (1 mol \%) in $\mathrm{CHCl}_{3}$, irradiation with a TQ 150 high pressure mercury lamp. ${ }^{\mathrm{b}} / \mathrm{solated}$ yields after column chromatography. ${ }^{\mathrm{C}}$ Determined by chiral HPLC analysis. ${ }^{\mathrm{d} P e r f o r m e d}$ under batch condition. 
Table 2: Scope of the continuous-flow photocyclization-asymmetric reduction domino sequence. ${ }^{a}$

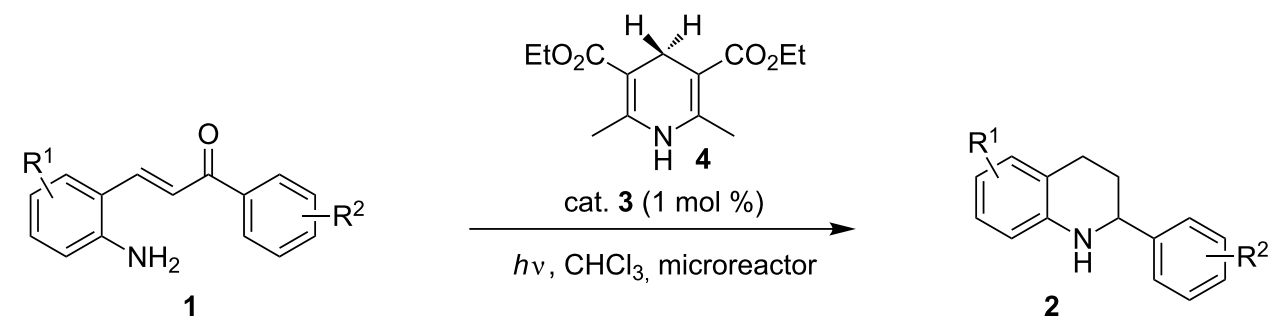

\begin{tabular}{|c|c|c|c|c|}
\hline Entry ${ }^{a}$ & Substrate 1 & Product 2 & Yield [\%] ${ }^{\mathrm{b}}$ & ee $[\%]^{c}$ \\
\hline 1 & 1a & $2 a$ & 82 & 94 \\
\hline 2 & $1 \mathrm{~b}$ & $2 b$ & 88 & 96 \\
\hline 3 & 1c & $2 c$ & 73 & 91 \\
\hline 4 & 1d & $2 d$ & 71 & 91 \\
\hline 5 & 1e & $2 e$ & 63 & 89 \\
\hline 6 & $1 \mathrm{f}$ & $2 f$ & 73 & 90 \\
\hline 7 & $1 \mathrm{~g}$ & $2 \mathrm{~g}$ & 75 & 88 \\
\hline 8 & 1h & $2 \mathrm{~h}$ & 64 & 90 \\
\hline
\end{tabular}


Table 2: Scope of the continuous-flow photocyclization-asymmetric reduction domino sequence. ${ }^{\text {a }}$ (continued)

9<smiles>Nc1ccc(Cl)cc1/C=C/C(=O)c1ccccc1</smiles>

1i

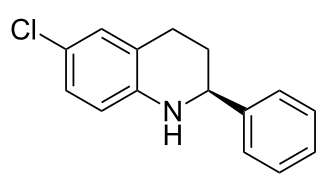

2i
57

91

aReaction conditions: $1,4\left(2.4\right.$ equiv), $3(1 \mathrm{~mol} \%)$ in $\mathrm{CHCl}_{3}(0.03 \mathrm{M})$ at $55^{\circ} \mathrm{C}$, flow rate $0.1 \mathrm{~mL} / \mathrm{min}$, residence time $=60 \mathrm{~min}$, irradiation with a TQ 150 high pressure mercury lamp. ${ }^{\mathrm{b}}$ Isolated yields after column chromatography. ${ }^{\mathrm{C}}$ Determined by chiral HPLC analysis.

uous-flow condition a variety of substituted 2 -aminochalcones underwent the photocyclization and the subsequent transfer hydrogenation to afford a series of differently substituted tetrahydroquinolines in good yields and with excellent enantioselectivities. This efficient protocol for the synthesis of tetrahydroquinoline from readily available 2 -aminochalcone provides an attractive alternative to the existing procedures and serves as a basis for further exploration of this new concept.

\section{References}

1. Keay, J. G. In Comprehensive Organic Synthesis; Trost, B. M.; Fleming, I., Eds.; Pergamon: Oxford, U.K., 1991; Vol. 8, p 579. doi:10.1016/B978-0-08-052349-1.00239-0

2. Katritzky, A. R.; Rachwal, S.; Rachwal, B. Tetrahedron 1996, 52, 15031-15070. doi:10.1016/S0040-4020(96)00911-8

3. Barton, D. H.; Nakanishi, K.; Cohn, O. M. Comprehensive Natural Products Chemistry; Elsevier: Oxford, U.K., 1999; Vol. 1-9.

4. Sridharan, V.; Suryavanshi, P. A.; Menéndez, J. C. Chem. Rev. 2011, 111, 7157-7259. doi:10.1021/cr100307m

5. Rueping, M.; Antonchick, A. P.; Theissmann, T. Angew. Chem., Int. Ed. 2006, 45, 3683-3686. doi:10.1002/anie.200600191

6. Rueping, M.; Theissmann, T.; Raja, S.; Bats, J. W. Adv. Synth. Catal. 2008, 350, 1001-1006. doi:10.1002/adsc.200800020

7. Rueping, M.; Sugiono, E.; Steck, A.; Theissmann, T. Adv. Synth. Catal. 2010, 352, 281-287. doi:10.1002/adsc.200900746

8. Rueping, M.; Theissmann, T. Chem. Sci. 2010, 1, 473-476. doi:10.1039/C0SC00206B

9. Rueping, M.; Stoeckel, M.; Sugiono, E.; Theissmann, T. Tetrahedron 2010, 66, 6565-6568. doi:10.1016/j.tet.2010.04.091

10. Rueping, M.; Theissmann, T.; Stoeckel, M.; Antonchick, A. P. Org. Biomol. Chem. 2011, 9, 6844-6850. doi:10.1039/c1ob05870c

11. Rueping, M.; Bootwicha, T.; Sugiono, E. Beilstein J. Org. Chem. 2012, 8, 300-307. doi:10.3762/bjoc.8.32

12. Guo, Q.-S.; Du, D.-M.; Xu, J. Angew. Chem., Int. Ed. 2008, 47, 759-762. doi:10.1002/anie.200703925

13. Han, Z.-Y.; Xiao, H.; Chen, X.-H.; Gong, L.-Z. J. Am. Chem. Soc. 2009, 131, 9182-9183. doi:10.1021/ja903547q

14. Ren, L.; Lei, T.; Ye, J.-X.; Gong, L.-Z. Angew. Chem., Int. Ed. 2012, 51, 771-774. doi:10.1002/anie.201106808

15. Tu, X.-F.; Gong, L.-Z. Angew. Chem., Int. Ed. 2012, 51, 11346-11349. doi:10.1002/anie.201204179

16. Patil, N. T.; Raut, V. S.; Tella, R. B. Chem. Commun. 2013, 49, 570-572. doi:10.1039/c2cc37623g
17. Wang, D.-S.; Chen, Q.-A.; Lu, S.-M.; Zhou, Y.-G. Chem. Rev. 2012, 112, 2557-2590. doi:10.1021/cr200328h

18. Ehrfeld, W.; Hessel, V.; Löwe, H. Microreactors: New Technology for Modern Chemistry; Wiley-VCH: Weinheim, Germany, 2000. doi:10.1002/3527601953

19. Wirth, T., Ed. Microreactors in Organic Synthesis and Catalysis; Wiley-VCH: Weinheim, Germany, 2008. doi:10.1002/9783527622856

20. Yoshida, J.-i. Flash Chemistry - Fast Organic Synthesis in Microsystems; Wiley-VCH: Weinheim, Germany, 2008.

21. Hessel, V.; Schouten, J. C.; Renken, A.; Wang, Y.; Yoshida, J.-i., Eds. Handbook of Micro Reactors; Wiley-VCH: Weinheim, Germany, 2009.

22. Luis, S. V.; Garcia-Verdugo, E., Eds. Chemical Reactions and Processes under Flow Conditions; Royal Society of Chemistry: Cambridge, U.K., 2010.

23. Matsushita, Y.; Ichimura, T.; Ohba, N.; Kumada, S.; Sakeda, K.; Suzuki, T.; Tanibata, H.; Murata, T. Pure Appl. Chem. 2007, 79, 1959-1968. doi:10.1351/pac200779111959

24. Coyle, E. E.; Oelgemöller, M. Photochem. Photobiol. Sci. 2008, 7, 1313-1322. doi:10.1039/b808778d

25. Oelgemöller, M.; Shvydkiv, O. Molecules 2011, 16, 7522-7550. doi:10.3390/molecules16097522

26. Aida, S.; Terao, K.; Nishiyama, Y.; Kakiuchi, K.; Oelgemöller, M. Tetrahedron Lett. 2012, 53, 5578-5581. doi:10.1016/j.tetlet.2012.07.143

27. Oelgemoeller, M. Chem. Eng. Technol. 2012, 35, 1144-1152. doi:10.1002/ceat.201200009

28. Knowles, J. P.; Elliott, L. D.; Booker-Milburn, K. I. Beilstein J. Org. Chem. 2012, 8, 2025-2052. doi:10.3762/bjoc.8.229

29. Oelgemöller, M.; Shvydkiv, O. Microphotochemistry: Photochemical Synthesis in Microstructured Flow Reactors. CRC Handbook of Organic Photochemistry and Photobiology; CRC Press, 2012; pp 125-178.

30. Neumann, M.; Zeitler, K. Org. Lett. 2012, 14, 2658-2661. doi:10.1021/ol3005529

31. Sakeda, K.; Wakabayashi, K.; Matsushita, Y.; Ichimura, T.; Suzuki, T.; Wada, T.; Inoue, Y. J. Photochem. Photobiol., A 2007, 192, 166-171. doi:10.1016/j.jphotochem.2007.05.019

32. You, S.-L. Chem.-Asian J. 2007, 2, 820-827. doi:10.1002/asia.200700081

33. Rueping, M.; Sugiono, E.; Schoepke, F. R. Synlett 2010, 852-865. doi:10.1055/s-0029-1219528

34. Rueping, M.; Dufour, J.; Schoepke, F. R. Green Chem. 2011, 13, 1084-1105. doi:10.1039/c1gc15027h

35. Zheng, C.; You, S.-L. Chem. Soc. Rev. 2012, 41, 2498-2518. doi:10.1039/c1cs15268h 
36. Richter, D.; Mayr, H. Angew. Chem., Int. Ed. 2009, 48, 1958-1961. doi:10.1002/anie.200804263

37. Zhu, X.-Q.; Liu, Y.-C.; Cheng, J.-P. J. Org. Chem. 1999, 64, 8980-8981. doi:10.1021/jo9905571

38. Liao, H.-H.; Hsiao, C.-C.; Sugiono, E.; Rueping, M. Chem. Commun. 2013, 49, 7953-7955. doi:10.1039/c3cc43996h

39. The glass microreactors (Type: LTF-V and LTF-VS) were purchased from Little Things Factory (http://www.LTF-GmbH.de). All glasswares used for this study are borosilica glass.

40. Ohnishi, Y.; Kagami, M.; Ohno, A. Chem. Lett. 1975, 4, 125-128. doi:10.1246/cl.1975.125

41. Inoue, Y.; Imaizumi, S.; Itoh, H.; Shinya, T.; Hashimoto, H.; Miyano, S. Bull. Chem. Soc. Jpn. 1988, 61, 3020-3022. doi:10.1246/bcsj.61.3020

\section{License and Terms}

This is an Open Access article under the terms of the Creative Commons Attribution License

(http://creativecommons.org/licenses/by/2.0), which permits unrestricted use, distribution, and reproduction in any medium, provided the original work is properly cited.

The license is subject to the Beilstein Journal of Organic Chemistry terms and conditions:

(http://www.beilstein-journals.org/bjoc)

The definitive version of this article is the electronic one which can be found at: doi:10.3762/bjoc. 9.284 